This document is the accepted manuscript version of the following article:

Guan, M., Annaheim, S., Li, J., Camenzind, M., Psikuta, A., \& Rossi, R. M. (2019). Apparent evaporative cooling efficiency in clothing with continuous perspiration: a sweating manikin study. International Journal of Thermal Sciences, 137, 446-455. https://doi.org/10.1016/ j.ijthermalsci.2018.12.017

This manuscript version is made available under the CC-BY-NC-ND 4.0

license http://creativecommons.org/1icenses/by-nc-nd/4.0/

\title{
Apparent evaporative cooling efficiency in clothing with continu- ous perspiration: a sweating manikin study
}

\author{
Manhao Guan ${ }^{1,2}$, Simon Annaheim², Jun Lii ${ }^{1} 3,4,{ }^{*}$, Martin Camenzind ${ }^{2}$, Agnes Psikuta², René Michel \\ Rossi2, * $^{2}$ \\ ${ }^{1}$ College of Fashion and Design, Donghua University, 200051, Shanghai, China \\ 2Empa, Swiss Federal Laboratories for Materials Science and Technology, Laboratory for Biomimetic \\ Membranes and Textiles, CH-9014, St. Gallen, Switzerland \\ ${ }^{3}$ Key Laboratory of Clothing Design and Technology, Donghua University, Ministry of Education, 200051, \\ Shanghai, China \\ ${ }^{4}$ Tongji University Shanghai Institute of Design and Innovation, Shanghai 200092, China \\ ${ }^{*}$ Correspondence and requests for materials should be addressed to J.L. (email: lijun@dhu.edu.cn) or R.R. \\ (email: rene.rossi@empa.ch)
}

\begin{abstract}
:
Apparent evaporative cooling efficiency has typically been determined by applying a pre-wetted fabric "skin" on a dummy ("manikin") simulating human thermal physiology, to understand the effective cooling components of body perspiration in clothing systems. This procedure is only a very rough approximation of real life, as the pre-wetted fabric does not have the capacity to continuously push extra moisture into the clothing layers, which would happen with continuous sweating of the body. In this study, a sweating torso was used to mimic different sweating situations $(100,175$ and $250 \mathrm{~g} / \mathrm{h})$ with twelve single-layer (SI) and multilayer (MU) clothing systems to understand the effect of continuous sweating and its interaction with clothing materials on cooling efficiency. Our experiments revealed that evaporative cooling efficiency is affected differently by continuous sweating when compared to pre-wetted fabric "skin" approaches. With continuous sweating, up to $15 \%\left(24 \mathrm{~W} \cdot \mathrm{m}^{-2}\right)$ cooling power came from the so-called "heat pipe effect" and/or wet conduction and $24 \%\left(44 \mathrm{~W} \cdot \mathrm{m}^{-2}\right)$ evaporative latent heat was gained from the environment. It was found that the increase of perspired moisture can affect evaporative cooling efficiency for hydrophilic materials in dual ways. For each $75 \mathrm{~g} / \mathrm{h}$ sweat rate increase, the in-plane moisture transfer can raise the evaporative cooling efficiency of Sls at least 3-12 \% and the transplanar moisture transfer may reduce the evaporative cooling efficiency by at least 2-7 \% and 2-9 \% for Sls and MUs, respectively. For hydrophobic materials, the evaporative cooling efficiency was less affected by different levels of perspiration due to low wicking. Results also showed the negative correlation of evaporative cooling efficiency of hydrophilic materials with fabric evaporative resistance and thickness. Our study contributes to the understanding of the effective sweat cooling power and evaporative latent heat from environment for the clothed human body with continuous sweating. It also provides insight into the interaction between liquid and water vapor transport, and material design for optimizing the evaporative cooling.
\end{abstract}

Keywords: thermoregulation; sweat; evaporation; wicking; evaporative cooling efficiency.

\section{Introduction}

Evaporative cooling of perspired moisture is a crucial pathway for heat dissipation in human thermoregulation, with clothing affecting the cooling mechanism as a barrier between the human body and the environment. People usually consider the weight change of clothed human body to estimate the evaporative cooling [1-5]. However, some studies [6,7] have demonstrated that the evaporative heat loss 
calculation based on mass loss might be misleading. In addition to the evaporative latent heat from the human body, the mass-based evaporative heat may also include an evaporative heat part from the environment, which does not contribute to the cooling of the human body. Thus, the calculation based on mass loss may overestimate body evaporative heat loss and underestimate body heat accumulation. Meanwhile, the mass-based calculation neglects the cooling benefits brought by microclimate heat pipe effect $^{1}$ [6] and wet conduction. Although these two parts of heat transfer do not contribute to mass loss, they still bring physiological cooling. Havenith et al. showed [7] that the cooling caused by heat pipe effect and wet conduction can be three times higher than the evaporative cooling. Through the classic body heat balance equation in human trials [8,9] or heat flux measurements of thermal manikins $[6,7]$, the sweat cooling power (also known as apparent evaporative heat loss), consisting of evaporative cooling and cooling caused by heat pipe effect and wet conduction, can be obtained. The ratio between the sweat cooling power and the mass-based evaporative heat is defined as the apparent evaporative cooling efficiency $[6,7,10]$. By comparing these two parts, the quantification of the components of sweat cooling power and mass-based evaporative heat can also be achieved.

Craig [11] found a decrease in apparent evaporative cooling efficiency with an increased clothing water content, but the extent of the decrease was not quantified. As liquid sweat transfers in two directions in clothing, i.e., the in-plane and transplanar transfer [12-14], later studies investigated the effect of perspired moisture distribution in clothing on the cooling efficiency. A thermal manikin study showed that when evaporation took place from the skin, the underwear and the outermost layer, the cooling efficiency was found to be $100 \%, 72 \%$ and $22 \%$, respectively [7]. Wang et al. [15] further showed that the cooling efficiency linearly decreased as moisture transported from the skin surface to the clothing layer. Some researchers [7] also qualitatively reasoned that, when the skin is not fully wet, the in-plane wicking of sweat from the skin may also have a positive effect by increasing the surface area of evaporation. However, no studies have provided experimental evidence on how the evaporative surface area increase, that is, how the in-plane transfer of moisture, influences the cooling efficiency. These previous studies contribute to the understanding of cooling efficiency in cases with the limited sweat supply. As shown in Fig.1a, the sweat may influence the cooling efficiency through two aspects: (I) increasing the evaporative distance from the skin through the transplanar transfer and (II) increasing evaporative area through the in-plane transfer.

Clothing materials also show their effect on the cooling efficiency. For evaporation from the "skin" surface of thermal manikin (at lower ambient temperatures, i.e., 10 and $20^{\circ} \mathrm{C}$ ), the cooling efficiency of permeable clothing was lower than that of impermeable clothing [6]. For evaporation at the clothing outer surface, the cooling efficiency was negatively related with clothing thermal insulation [16]. As sweat transported from the skin to the clothing layer, material thickness has a negative effect in maintaining a high cooling efficiency [15].

\footnotetext{
${ }^{1}$ Microclimate heat pipe effect: evaporation of moisture at the skin that condenses in and releases heat to the clothing layers without being transferred to the environment.
} 

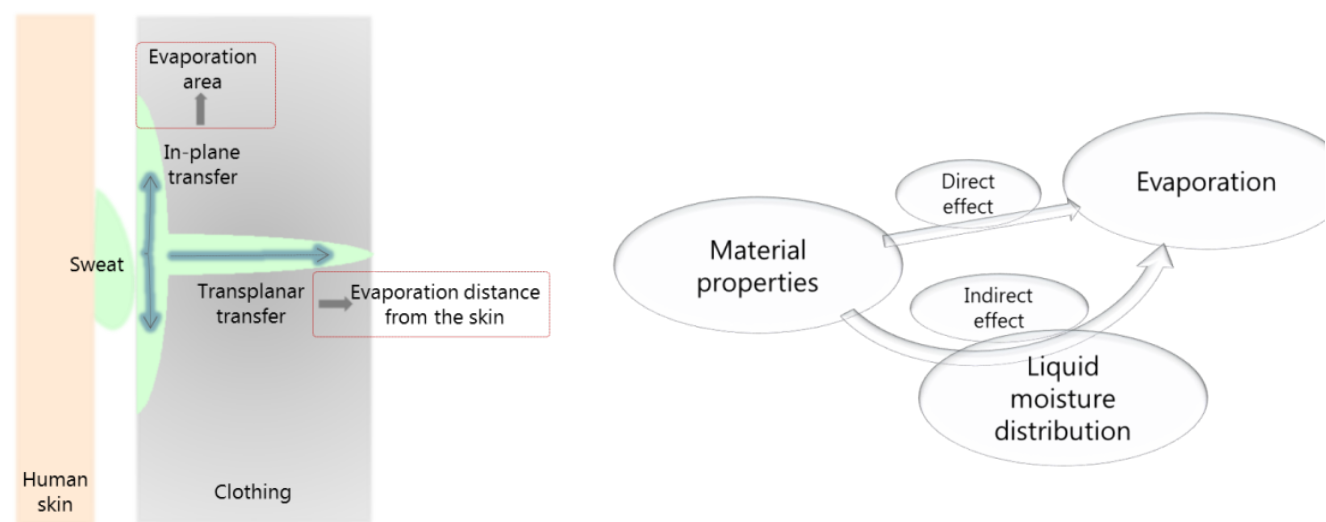

Figure 1. (a) In-plane and transplanar transfer of sweat and its effect on evaporation. In-plane transfer increases evaporation area. Transplanar transfer increases evaporation distance from the skin. (b) Direct and indirect effect of material properties on moisture evaporation. Direct effect: Materials (e.g. porosity) can influence water evaporation directly by evaporative resistance; indirect effect: Materials affect liquid moisture transport and distribution (i.e. hydrophilicity), thereby influencing evaporation.

However, these previous studies usually used pre-wetted underwear and/or pre-wetted fabric "skin" to investigate the cooling efficiency, in which sweating was simulated through wetting the fabric by spraying it with distilled water before testing $[6,7,15]$. This pre-wetted method does not consider continuously pushing extra moisture into the clothing layers and mainly focuses on water evaporation. But in practice, individuals sweat continuously and often profusely, e.g., in activities of high intensity. This unlimited supply of liquid moisture will lead to the concurrence of liquid water transport and evaporation. As shown in Fig. 1b, clothing materials can influence water evaporation directly by evaporative resistance. However, materials may also affect liquid water transport and distribution, which in turn affects evaporation. The latter indirect effect on evaporation has not been systematically studied. One study considered continuous sweating $[10,17]$ proposed that when the relative evaporation (R.E.) (i.e., the ratio between the required evaporation cooling and the evaporative capacity of the air) was low, sweat was not transferred to the clothing and a higher proportion was evaporated on the skin. This resulted in higher cooling efficiency. However, the limitations of this study may include (I) only one hydrophilic material was considered, (II) the sweat rate was controlled to keep in balance with the evaporation rate, without considering excessive liquid sweating.

The aim of our study is to understand the apparent evaporative cooling efficiency of a continuously sweating person, quantifying the effective cooling power of sweating and the evaporative heat from environment. For this, different levels of sweat rates were chosen to investigate the effect of perspired moisture on the apparent evaporative cooling efficiency and a wide range of clothing systems were applied to explore the interaction between perspired moisture and material properties. This study will contribute to the understanding of the real cooling power caused by sweating and accurate evaluation of heat stress in intensive activities.

\begin{tabular}{|c|c|c|c|}
\hline Nomenclature & & $P_{a}$ & Vapor pressure in the environment, $\mathrm{kPa}$ \\
\hline Latine letters & & $P_{s k, s}$ & $\begin{array}{l}\text { Saturated vapor pressure at the torso sur- } \\
\text { face, } \mathrm{kPa}\end{array}$ \\
\hline$h_{e}$ & $\begin{array}{l}\text { Mass transfer coefficient of cloth- } \\
\text { ing material, } \mathrm{g} \cdot \mathrm{m}^{-2} \cdot \mathrm{h}^{-1} \cdot \mathrm{kPa}^{-1}\end{array}$ & R.E. & Relative evaporation, dimensionless \\
\hline$i_{m}$ & $\begin{array}{l}\text { Permeability index of clothing ma- } \\
\text { terial, dimensionless }\end{array}$ & $R_{c t}$ & $\begin{array}{l}\text { Thermal resistance of clothing material, } \\
10^{-3} \cdot \mathrm{K} \cdot \mathrm{m}^{2} \mathrm{~W}\end{array}$ \\
\hline
\end{tabular}




\begin{tabular}{|c|c|c|c|}
\hline$m_{\text {clothed torso }}$ & $\begin{array}{l}\text { Weight change of clothed torso } \\
\text { due to sweating, } g\end{array}$ & $R_{e t}$ & $\begin{array}{l}\text { Evaporative resistance of clothing mate- } \\
\text { rial, } \mathrm{m}^{2} \cdot \mathrm{Pa} / \mathrm{W}\end{array}$ \\
\hline$\dot{m}_{\text {evap }}$ & Evaporation rate of sweat, $\mathrm{g} / \mathrm{h}$ & $T H L_{d r y}$ & $\begin{array}{l}\text { Total heat loss in P1 (dry heat loss), } \\
\mathrm{W} / \mathrm{m}^{2}\end{array}$ \\
\hline$m_{\text {evap }}$ & Evaporation amount of sweat, $\mathrm{g}$ & $T H L_{w e t}$ & $\begin{array}{l}\text { Total heat loss in P2 (combination of dry } \\
\text { heat loss and heat loss caused by sweat- } \\
\text { ing), W/m² }\end{array}$ \\
\hline$\dot{m}_{\text {evap, } \max }$ & Maximum evaporation rate, $\mathrm{g} / \mathrm{h}$ & Greek letters & \\
\hline$m_{\text {sweat }}$ & Sweat amount, $\mathrm{g}$ & $\lambda$ & $\begin{array}{l}\text { Latent heat of sweat evaporation, } 0.673 \\
\mathrm{~W} \cdot \mathrm{h} \cdot \mathrm{g}^{-1} \text { at } 35^{\circ} \mathrm{C}\end{array}$ \\
\hline$A_{\text {torso }}$ & Effective surface area of torso, $\mathrm{m}^{2}$ & $\eta$ & $\begin{array}{l}\text { Apparent evaporative cooling efficiency, } \\
\text { dimensionless }\end{array}$ \\
\hline$E_{a p p}$ & $\begin{array}{l}\text { Apparent evaporative heat loss, } \\
\mathrm{W} / \mathrm{m}^{2}\end{array}$ & $\Delta \eta$ & $\begin{array}{l}\text { Variation of apparent evaporative cooling } \\
\text { efficiency, dimensionless }\end{array}$ \\
\hline$E_{\text {env }}$ & $\begin{array}{l}\text { Evaporative heat from environ- } \\
\text { ment, } \mathrm{W} / \mathrm{m}^{2}\end{array}$ & & \\
\hline$E_{\text {heat pipe }}$ & $\begin{array}{l}\text { Heat loss caused by heat pipe ef- } \\
\text { fect, } W / \mathrm{m}^{2}\end{array}$ & & \\
\hline$E_{\text {mass }}$ & $\begin{array}{l}\text { Evaporative cooling potential, } \\
\mathrm{W} / \mathrm{m}^{2}\end{array}$ & & \\
\hline$E_{\text {non-evap }}$ & Non-evaporative heat loss, $\mathrm{W} / \mathrm{m}^{2}$ & & \\
\hline$E_{\text {real }}$ & Real evaporative heat loss, $\mathrm{W} / \mathrm{m}^{2}$ & & \\
\hline$E_{\text {wet cond }}$ & $\begin{array}{l}\text { Heat loss caused by wet conduc- } \\
\text { tion, } \mathrm{W} / \mathrm{m}^{2}\end{array}$ & & \\
\hline
\end{tabular}

\section{Methods}

\subsection{Measurement}

\subsubsection{Torso manikin experiment}

\section{(1) Torso manikin}

To accurately determine the heat and moisture transfer between the clothed human body and its surrounding environment, measurements were performed on a sweating torso manikin (Fig. 1) (Swiss Federal Laboratories for Materials Science and Technology, St. Gallen, Switzerland) [18, 19]. The torso consists of a multi-layered main cylinder with the dimension of an adult human torso and two heated aluminum guards. The main cylinder can maintain a constant surface temperature by controlling heat input. The two guards are used to prevent heat losses in the upward and downward directions. Fiftyfour sweating outlets are evenly distributed over the surface of the main cylinder and are connected to internal controlled valves to simulate various sweating levels ${ }^{2}$. Other detailed information regarding the torso can be found in the literature [20,21].

\footnotetext{
${ }^{2}$ As the water is the main component $(\approx 99 \%)$ of the sweat and other minor components may complicate the heat and moisture transfer analyses, we used distilled water to simulate sweat in the current research stage.
} 


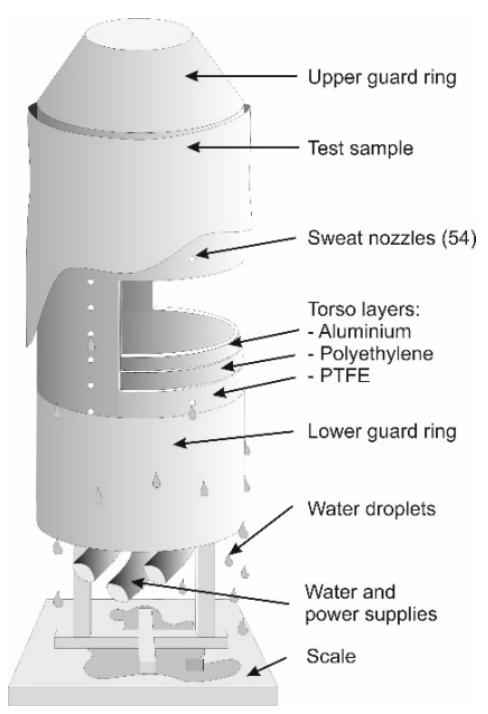

Figure 2. Schematic diagram of the sweating torso manikin. PTFE, polytetrafluoroethylene.

\section{(2) Clothing materials}

Twelve common commercially-available clothing material systems with different physical properties were selected, including seven single-layered (SI) and five multi-layered (MU) systems. Based on previous studies on the effect of material properties on the evaporative cooling efficiency and the application of liquid sweat in our study, material weight, thickness, thermal resistance $\left(R_{c t}\right)$, evaporative resistance $\left(R_{e t}\right)$, permeability index $\left(i_{m}\right)$ and hydrophilicity/hydrophobicity were chosen as the possible influential material properties (Table 1). The hydrophilicity and hydrophobicity of materials were identified by measuring the contact angle of the innermost side of material systems. According to the measured contact angle, pho-SI2, pho-SI5, pho-MU9 and pho-MU10 are hydrophobic materials, while others are hydrophilic materials.

Table 1 Physical properties of clothing materials

\begin{tabular}{|c|c|c|c|c|c|c|c|c|}
\hline \multirow{2}{*}{\multicolumn{2}{|c|}{ Clothing Systems }} & \multirow[b]{2}{*}{ Fiber Type } & \multicolumn{6}{|c|}{ Physical Properties } \\
\hline & & & $\begin{array}{c}\text { Weight } \\
\text { a } \\
\left(\mathrm{g} / \mathrm{m}^{2}\right) \\
\end{array}$ & $\begin{array}{l}\text { Thickness }^{\mathrm{b}} \\
\quad(\mathrm{mm})\end{array}$ & $\begin{array}{c}\text { Contact an- } \\
\text { gle }^{\mathrm{c}} \\
\left({ }^{\circ}\right)\end{array}$ & $\begin{array}{c}\mathrm{R}_{\mathrm{ct}}{ }^{\mathrm{d}} \\
\left(10^{-3} \cdot \mathrm{K} \cdot \mathrm{m}^{2} \mathrm{~W}\right)\end{array}$ & $\begin{array}{c}\mathrm{Ret}_{\mathrm{et}}^{\mathrm{e}} \\
\left(\mathrm{m}^{2} \cdot \mathrm{Pa} / \mathrm{W}\right)\end{array}$ & $\mathrm{i}_{\mathrm{m}}^{\mathrm{f}}$ \\
\hline \multirow{7}{*}{$\begin{array}{l}\text { Single- } \\
\text { layered } \\
\text { clothing } \\
\text { (SI) }\end{array}$} & $\begin{array}{l}\text { phi- } \\
\text { SI1 }\end{array}$ & $\begin{array}{l}\text { meta-aramid/fire retardant } \\
\text { (FR) viscose }\end{array}$ & 197 & 0.4 & 0 & 10.8 & 2.1 & 0.30 \\
\hline & $\begin{array}{l}\text { phi- } \\
\text { SI2 }\end{array}$ & $\begin{array}{l}\text { aramid/ lyocell/ modacrylic/ } \\
\text { anti-static fiber }\end{array}$ & 241.6 & 0.6 & 0 & 13.4 & 2.7 & 0.30 \\
\hline & $\begin{array}{l}\text { pho- } \\
\text { SI2 }\end{array}$ & $\begin{array}{l}\text { aramid/ lyocell/ modacrylic/ } \\
\text { anti-static fiber }\end{array}$ & 253.1 & 0.7 & 128.6 & 13.2 & 2.7 & 0.29 \\
\hline & $\begin{array}{l}\text { phi- } \\
\text { SI3 }\end{array}$ & $\begin{array}{l}\text { meta-aramid/para-aramid/ } \\
\text { antistatic fibre }\end{array}$ & 154.7 & 0.3 & 0 & 11.7 & 2 & 0.34 \\
\hline & $\begin{array}{l}\text { phi- } \\
\text { SI4 }\end{array}$ & $\begin{array}{l}\text { meta-aramid/para-aramid/ } \\
\text { antistatic fibre }\end{array}$ & 229.8 & 0.4 & 0 & 12.7 & 3.2 & 0.24 \\
\hline & $\begin{array}{l}\text { pho- } \\
\text { SI5 }\end{array}$ & FR Modacrylic/FR Cotton & 367.3 & 0.7 & 130.7 & 16.6 & 3.4 & 0.29 \\
\hline & $\begin{array}{l}\text { pho- } \\
\text { SI6 }\end{array}$ & FR Cotton & 366.8 & 0.8 & 0 & 14.5 & 4.4 & 0.20 \\
\hline \multirow{5}{*}{$\begin{array}{l}\text { Multi- } \\
\text { layered } \\
\text { clothing } \\
(\mathrm{MU})\end{array}$} & $\begin{array}{l}\text { phi- } \\
\text { MU7 }\end{array}$ & $\begin{array}{c}\text { aramid/beltron+ PTFE coated } \\
\text { meta-aramid+ fleece+ meta- } \\
\text { aramid/viscose }\end{array}$ & 635.2 & 3.2 & 0 & 82.7 & 15.6 & 0.32 \\
\hline & $\begin{array}{l}\text { phi- } \\
\text { MU8 }\end{array}$ & $\begin{array}{l}\text { Meta-aramid + PU liner on } \\
\text { meta-aramid+ aramid }\end{array}$ & 592.1 & 3.8 & 0 & 95.4 & 23.9 & 0.24 \\
\hline & $\begin{array}{l}\text { pho- } \\
\text { MU9 }\end{array}$ & $\begin{array}{l}\text { FR viscose/meta-aramid/anti- } \\
\text { static+ PU coated meta-ara- } \\
\text { mid/FR viscose+FR vi- } \\
\text { scose/meta-aramid }\end{array}$ & 587.8 & 2 & 130.8 & 46.6 & 9.4 & 0.30 \\
\hline & $\begin{array}{l}\text { pho- } \\
\text { MU10 }\end{array}$ & $\begin{array}{l}\text { FR viscose/meta-aramid/ an- } \\
\text { tistatic+ PTFE coated meta- } \\
\text { aramid/FR viscose + FR vi- } \\
\text { scose/meta-aramid }\end{array}$ & 599.8 & 2.2 & 130.2 & 49.3 & 10 & 0.30 \\
\hline & $\begin{array}{l}\text { phi- } \\
\text { MU11 }\end{array}$ & $\begin{array}{l}\text { Meta-aramid+ PTFE coated } \\
\text { meta-aramid/para-aramid/ba- } \\
\text { sofil + meta-aramid quilted } \\
\text { with meta-aramid/ FR viscose }\end{array}$ & 493 & 2.3 & 0 & 71 & 16.8 & 0.25 \\
\hline
\end{tabular}


*Physical properties were measured according to aSO 3801:1977 (by weighing balance of Mettler-Toledo, Switzerland), bISO 5084:1996 (by thickness tester of Frank-PTI, Germany), 'ASTM D7334 - 08(2013). If the contact angle of a material is $0^{\circ}$, it is categorized as hydrophilic If the contact angle is greater than $90^{\circ}$, the material is categorized as hydrophobic, $d, e, f$ ISO 11092:2014 (by hot plate tester of Hohenstein Institute, Germany. [22-24] For MU, the fiber type is shown as outer layer+middle layer+inner layer. PTFE: polytetrafluorethylene; PU: polyurethane.

\section{(3) Experimental design}

Experiments were performed in a climatic chamber with air temperature $20.0 \pm 0.5^{\circ} \mathrm{C}$, relative humidity $50 \pm 2 \%$ and air velocity $0.65 \pm 0.10 \mathrm{~m} / \mathrm{s}$. The experiment was designed to include two consecutive phases with a constant surface temperature of $35^{\circ} \mathrm{C}$. The heat input required to achieve the constant temperature was measured. In phase one (P1), the torso was kept in the dry state for one hour. In phase two (P2), it began to sweat at a pre-set sweat rate for two hours. Three sweat rates 100, 175 and $250 \mathrm{~g} / \mathrm{h}$ were chosen. Two weighing scales were used to record the real-time weight of the sweat tank (balance I, accuracy: $0.1 \mathrm{~g}$, Mettler-Toledo SB8001, Mettler-Toledo GmbH, Greifensee, Switzerland) and weight of clothed torso (balance II, Mettler-Toledo KCC150, Mettler-Toledo GmbH, Greifensee, Switzerland, accuracy: $1 \mathrm{~g}$ ). Before tests, clothing materials were preconditioned in the climatic chamber for at least 24 hours. Due to the complexity of moisture effect, we considered in this study that materials contacted the torso surface homogeneously without an air gap. Thus, we were able to investigate liquid sweat transfer and phase-change in clothing-human body system. The materials were prepared with the same dimensions to guarantee homogeneous pressure between material layers.

All the heat and moisture transfer data were collected during the steady state. For all materials, during the last 30 mins of each phase, the coefficient of variation (CV) of the mean torso surface temperature was less than $0.3 \%$ and the $C V$ for the heating power of the torso was less than $5.8 \%$. In accordance with previous studies [25], we assumed that the heat transfer of clothed torso during the period of time reached steady state. For each sweat rate, at least three replicates of the fabric were tested on the sweating torso, guaranteeing the $\mathrm{CV}$ of heating power among the three repetition tests to be less than $6.8 \%$. For all tests, the normalized root-mean-square deviation (NRMSD) of the evaporation rate $\left(\dot{m}_{\text {evap }}\right)$ during the last 30 minutes of P2 was lower than $1.1 \%$, thus we considered that $\dot{m}_{\text {evap }}$ was constant during this period and the evaporation process reached the steady state. The calculation of $\dot{m}_{\text {evap }}$ is introduced in 2.2.1.

In addition, a thermographic camera (FLIR A40M, Flir Systems Inc., Wilsonville, Oregon, USA) was used to record the thermal images of the clothed manikin, as to observe the sweat transport and evaporation.

\subsubsection{X-ray tomographic measurements}

To investigate the in-plane and transplanar wicking between different sweat rates, X-ray tomographic measurements for selected materials (phi-SI4 and phi-MU8) were performed according to an established procedure [26]. Material selection was done based on the apparent evaporative cooling efficiency observed during the torso experiments. The test material was fixed on a horizontal flat sweating skin model and then exposed to X-ray for the measurements. This is our existing skin model that is closest to the torso measurement and can be used to measure the in-plane and transplanar wicking. To obtain steady moisture distribution, the measurements were performed for 2 hours, which was the same duration with $\mathrm{P} 2$ of torso measurements. Each case was repeated twice.

\subsection{Calculations}

\subsubsection{Calculation of cooling efficiency}

The apparent evaporative cooling efficiency ( $\eta$ ) was calculated as eqn. (1) [6] 


$$
\eta=\frac{E_{a p p}}{E_{\text {mass }}}
$$

where $E_{a p p}$ is the apparent evaporative heat loss, $\mathrm{W} \cdot \mathrm{m}^{-2}$, calculated as eqn. (2); $E_{\text {mass }}$ is the evaporative cooling potential, $\mathrm{W} \cdot \mathrm{m}^{-2}$, calculated as eqn. (3).

$$
\begin{gathered}
E_{a p p}=T H L_{\text {wet }}-T H L_{d r y} \\
E_{\text {mass }}=\dot{m}_{\text {evap }} \times \lambda
\end{gathered}
$$

In eqn. (2), $T H L_{d r y}$ is the total heat loss in P1, i.e., the dry heat loss, $\mathrm{W} \cdot \mathrm{m}^{-2} ; T H L_{w e t}$ is the total heat loss in P2, i.e., the combination of dry heat loss and heat loss caused by sweating, $\mathrm{W} \cdot \mathrm{m}^{-2}$. In eqn. (3), $\dot{m}_{\text {evap }}$ is the evaporation rate of sweat, $\mathrm{g} \cdot \mathrm{h}^{-1}$, obtained through the weighing scales. Through the real time measurement of scale I and II, the sweat amount $\left(m_{\text {sweat }}\right)$ and the weight change of clothed torso due to sweating ( $\left.m_{\text {clothed torso }}\right)$ can be obtained. According to the relationship among the weights (eqn. (4)), the amount of evaporative sweat $\left(m_{\text {evap }}\right)$ can be obtained. Then, $\dot{m}_{\text {evap }}$ was calculated as the slope of $m_{\text {evap }}$ against time. $\lambda$ is the latent heat of sweat evaporation, $0.673 \mathrm{~W} \cdot \mathrm{h} \cdot \mathrm{g}^{-1}$ at $35^{\circ} \mathrm{C}$.

$$
m_{\text {sweat }}=m_{\text {clothed torso }}+m_{\text {evap }}
$$

\subsubsection{Quantification of $E_{n o n-e v a p}$ and $E_{\text {env }}$}

The heat transfer components in the apparent evaporative cooling efficiency ( $\eta$ ) are present in eqn. (5).

$$
\eta=\frac{E_{\text {app }}}{E_{\text {mass }}}=\frac{E_{\text {real }}+E_{\text {non-evap }}}{E_{\text {real }}+E_{\text {env }}}
$$

The apparent evaporative heat loss $E_{a p p}$ consists of the real evaporative heat loss $E_{\text {real }}$ and the heat loss caused by heat pipe effect $\left(E_{\text {heat pipe }}\right)$ and wet conduction ( $\left.E_{\text {wet cond }}\right)$. The latter two are collectively referred to non-evaporative heat loss $E_{\text {non-evap }}$ in this study. The evaporative cooling potential $E_{\text {mass }}$ consists of the real evaporative heat loss $E_{\text {real }}$ and the evaporative heat from environment $E_{\text {env }}$. Thus, the difference between $E_{a p p}$ and $E_{\text {mass }}$ is the difference between $E_{\text {non-evap }}$ and $E_{\text {env }}$ (eqn. (6)).

$$
E_{\text {app }}-E_{\text {mass }}=E_{\text {non-evap }}-E_{\text {env }}
$$

If $E_{a p p}>E_{\text {mass }}$, the difference between $E_{a p p}$ and $E_{\text {mass }}$ is the minimum value of $E_{\text {non-evap }}$ when assuming that $E_{\text {env }}$ is zero; if $E_{a p p}<E_{\text {mass }}$, the difference is the minimum value of $E_{\text {env }}$ when assuming that $E_{\text {non-evap }}$ is zero. The real value of $E_{\text {non-evap }}$ and $E_{\text {env }}$ could be higher than the calculated minimum value because $E_{\text {env }}$ and $E_{\text {non-evap }}$ could be above zero. But the minimum value is what can be obtained based on the current technical means and can provide effective information on heat components relevant to evaporation.

$|\eta-1|$ is the minimum value of $\frac{E_{\text {non-evap }}}{E_{\text {mass }}}$ or $\frac{E_{\text {env }}}{E_{\text {mass }}}($ eqn. $(7))$ and also the error ratio of traditional evaporative heat loss determination based on mass loss.

$$
\eta-1=\frac{E_{\text {non-evap }}-E_{\text {env }}}{E_{\text {mass }}}
$$

\subsubsection{Calculation of relative evaporation}

The relative evaporation ( $R . E$.), which is an indication of the skin wettedness, was calculated as eqn. (8) [10], in which $\dot{m}_{\text {evap,max }}$ is the maximum evaporative capacity for the clothed torso, $\mathrm{g} / \mathrm{h}$.

$$
\text { R.E. }=\frac{\dot{m}_{\text {evap }}}{\dot{m}_{\text {evap, } \max }}
$$


$\dot{m}_{\text {evap,max }}$ was calculated according to eqn. (9). $A_{\text {torso }}$ is the effective surface area of torso cylinder, $\mathrm{m}^{2}$; $P_{s k, s}$ is the saturated vapor pressure at the torso surface, $\mathrm{kPa} ; P_{a}$ is the vapor pressure in the environment, $\mathrm{kPa} ; h_{e}$ is the mass transfer coefficient of material, $\mathrm{g} \cdot \mathrm{m}^{-2} \cdot \mathrm{h}^{-1} \cdot \mathrm{kPa}^{-1}$, calculated based on the ISO evaporative resistance measurements [24] according to eqn. (10). $R_{e t}$ is the material intrinsic evaporative resistance, $\mathrm{m}^{2} \cdot \mathrm{kPa} / \mathrm{W} ; \lambda$ is the latent heat of sweat evaporation, $0.673 \mathrm{~W} \cdot \mathrm{h} \cdot \mathrm{g}^{-1}$ at $35^{\circ} \mathrm{C} . \mathrm{h}_{e, b l}$ is the mass transfer coefficient of the boundary layer, $\mathrm{g} \cdot \mathrm{m}^{-2} \cdot \mathrm{h}^{-1} \cdot \mathrm{kPa}^{-1}$, calculated according to the Lewis relationship as eqn. (11). LR is the Lewis coefficient; $h_{c, b l}$ is the convective heat transfer coefficient of the boundary layer, $\mathrm{g} \cdot \mathrm{m}^{-2} \cdot \mathrm{h}^{-1} \cdot{ }^{\circ} \mathrm{C}-1$, calculated based on the nude torso measurement.

$$
\begin{gathered}
\dot{m}_{\text {evap }, \text { max }}=\frac{A_{\text {torso }} \times\left(P_{s k, s}-P_{a}\right)}{1 / h_{e}+1 / h_{e, b l}} \\
\mathrm{~h}_{e}=\frac{1}{R_{e t} \times \lambda}(10) \\
h_{e, b l}=\frac{L R \times h_{c, b l}}{\lambda}
\end{gathered}
$$

\subsection{Statistical analyses}

Statistical analyses [27] were performed using the Statistical Package for the Social Sciences version 23.0 (IBM, Armonk, NY, USA). One-sample T test was first performed to identify the significant difference between the calculated apparent evaporative cooling efficiency and unity. The separate effect of sweat rate on apparent evaporative cooling efficiency was investigated through one-way analysis of variance (ANOVA) and followed with Tukey's honestly significant difference (HSD) or Tamhane's T2 post-hoc tests. The effect of material properties on apparent evaporative cooling efficiency were investigated with multiple linear regression. The force enter method was chosen for predictor selection. The multicollinearity assessment, casewise diagnostics, assumptions of linearity and homoscedasticity and normality of residuals were also investigated for the multiple linear regression models.

\section{Results and Discussion}

\subsection{Components of effective cooling and evaporative heat}

Fig. 3 presents the minimum non-evaporative heat loss $\left(E_{\text {non-evap }}\right)$ and the minimum environmental evaporative heat $\left(E_{\text {env }}\right)$. At least $0.5-23.7 \mathrm{~W} \cdot \mathrm{m}^{-2}\left(0.3-15.3 \%^{3}\right)$ effective cooling comes from $E_{\text {non-evap }}$ and at least $0.3-43.7 \mathrm{~W} \cdot \mathrm{m}^{-2}(0.2-24.2 \%)$ evaporative heat is $E_{\text {env }}$. The percentages also clearly demonstrate the error ratios of traditional evaporative heat loss determination based on mass loss (-24.2$15.3 \%)$.

\subsubsection{Heat transfer components}

\section{(1) Components of effective cooling}

For hydrophilic SIs, we assumed that for non-evaporative heat loss there was only wet conduction $\left(E_{\text {wet cond }}\right)$ with no heat pipe effect occurring, since no condensation on material surfaces was observed after tests. Overall, Sls showed $2.1-15.6 \mathrm{~W} \cdot \mathrm{m}^{-2} E_{\text {wet cond }}$, i.e., the moisture increased the heat conduction by $1-8 \%$. This percentage is in line with previous studies (<3-9\%) [6, 28, 29]. For hydrophilic MUs, due to the condensation observed on the inner side of outer layers after tests, we considered that the non-evaporative heat loss occurred via both wet conduction and heat pipe effect. Overall, MUs showed 7.7-21.1 W. $\mathrm{m}^{-2} E_{\text {non-evap }}$. Since the $E_{\text {non-evap }}$ increased by up to $21 \%$ compared to the dry heat loss,

$3 \%:(\eta-1)$, the corresponding average minimum percentage of $\frac{E_{\text {non-evap }}}{E_{\text {mass }}}$ and $\frac{E_{\text {env }}}{\boldsymbol{E}_{\text {mass }}}$. 
which was remarkably higher than the possible increase of wet conduction based on previous studies (i.e., < 3-9\%), we may infer that there must be heat pipe effect for these MU cases, which is in line with our observed condensation. In our study, the permeability index $\left(i_{m}\right)$ range of SIs and MUs is $0.20-0.34$ and we consider that they are comparable with the permeable clothing in previous studies $\left(i_{m}: 0.25-\right.$ 0.51). In previous thermal manikin studies with the pre-wetted fabric "skin" [6, 7], the permeable clothing did not show the non-evaporative heat loss (i.e., the cooling efficiency $\eta \leq 100 \%$, incl. $89 \%$ with $p<$ 0.05 and $97 \%-102 \%$ without significance). The reason for the higher $E_{\text {non-evap }}$ in our cases (i.e., $\eta>$ $100 \%$, incl. $102 \%-113 \%$ with $p<0.05)$ could be that the supply-unlimited sweat transferred to the material layer, causing wet conduction and provided higher possibility of evaporation-condensation (heat pipe effect). But in pre-wetted "skin" studies with lower air temperature [6, 30], there was 13.8$15.1 \mathrm{~W} \cdot \mathrm{m}^{-2} E_{\text {non-evap }}$, demonstrating that the lower air temperature also making the wet conduction and heat pipe effect significant.

Wissler et al. [31] developed a theoretical model of heat and moisture transport considering evaporationcondensation (heat pipe effect) in multi-layer garments. According to this model, condensation within the garment can facilitate evaporation from the skin. Based on this model, we calculated the maximum evaporative heat loss for MUs and found that the maximum evaporative heat loss is lower than the apparent evaporative heat loss at sweat rate 175 and $250 \mathrm{~g} / \mathrm{h}$. Take phi-MU7 as an example, the maximum evaporative heat loss according to the Wissler model was $205 \mathrm{~W} / \mathrm{m}^{2}$ while the apparent evaporative heat loss at sweat rate 175 and $250 \mathrm{~g} / \mathrm{h}$ were 261 and $280 \mathrm{~W} / \mathrm{m}^{2}$, respectively. Thus, according to the model, we can infer that there was condensation within the material to increase the heat loss, which agrees with our observed condensation. However, it should be noted that, in our study, since the locus of evaporation can change due to wicking process (which the model does not take into account), the environment may provide evaporative heat and this amount of heat may be greater than the non-evaporative heat loss, thus the non-evaporative heat loss may not be shown in Fig. 3 (e.g., phi-MU8 at sweat rate 175 and $250 \mathrm{~g} / \mathrm{h}$ ).

\section{(2) Environment evaporative heat}

Overall, hydrophilic Sls showed up to $29.2 \mathrm{~W} \cdot \mathrm{m}^{-2} E_{\text {env }}$ (i.e., $\mathrm{\eta}<100 \%$, incl. $87 \%-97 \%, \mathrm{p}<0.05$ ) while in a previous thermal manikin study with the pre-wetted "skin" [7], the single-layer permeable clothing did not show $E_{\text {env }}$ (i.e., $\eta=100 \%$, incl. $99 \%-102 \%$ without significance). Hydrophilic MUs showed the same message. The $E_{\text {env }}$ of hydrophilic MUs was up to $38.2 \mathrm{~W} \cdot \mathrm{m}^{-2}$ while the double-layer permeable clothing with pre-wetted "skin" showed $16.7 \mathrm{~W} / \mathrm{m}^{2} E_{\text {env }}$. The higher $E_{\text {env }}$ in our study was due to the full direct contact between the torso surface and the material, liquid sweat was transferred towards the clothing outer layers with the supply-unlimited sweating and thus caused a high environment evaporative heat. This inference could also be proved by the increased environmental evaporative heat with pre-wetted underwear and outerwear. For pre-wetted "skin", underwear and outerwear, the environmental evaporative heat increased from 16.7 to 31.3 and $59.2-69.3 \mathrm{~W} / \mathrm{m}^{2}$.

The present study provides experimental evidence that the non-evaporative heat loss and the environment evaporative heat (i.e., apparent evaporative cooling efficiency) with continuous sweating behaves differently from that with pre-wetted fabric "skin". The comparisons demonstrate that continuous sweating (I) provides unlimited water, may strengthening wet conduction and heat pipe effect; (2) considers the changes of evaporation locus from the skin, may allowing the environment more likely to provide the evaporative heat.

\subsubsection{Variation with sweat rate}

For hydrophilic SIs, when sweat rate increased from 100 to $175 \mathrm{~g} / \mathrm{h}$, the increase of $E_{\text {wet cond }}$ was higher than the increase of $E_{\text {env }}\left(3.9-20.8 \mathrm{~W} \cdot \mathrm{m}^{-2}, \mathrm{p}<0.001\right)$, i.e., the moisture benefited the wet conduction 
from the human body more than the environmental evaporative heat. When sweat rate continued increasing to $250 \mathrm{~g} / \mathrm{h}$, the increase of $E_{\text {env }}$ was higher than the increase of $E_{\text {wet cond }}\left(3.3-26.5 \mathrm{~W} \cdot \mathrm{m}^{-2}, \mathrm{p}<\right.$ 0.001 ), i.e., the moisture benefited the environmental evaporative heat more compared to the wet conduction from the human body. For hydrophilic phi-MU7 and phi-MU11, when sweat rate increased to $250 \mathrm{~g} / \mathrm{h}$, the increase of $E_{\text {env }}$ was higher than the increase of $E_{\text {non-evap }}\left(18.6-21.5 \mathrm{~W} \cdot \mathrm{m}^{-2}, \mathrm{p}<0.001\right)$. phiMU8 also showed higher increase of $E_{\text {env }}$ with 18.4 and $20.8 \mathrm{~W} \cdot \mathrm{m}^{-2}$, respectively $(\mathrm{p}<0.05)$ when sweat rate increased to 175 and $250 \mathrm{~g} / \mathrm{h}$. For hydrophobic materials, pho-SI2 showed the increase of $E_{\text {env }}$ $\left(13.2 \mathrm{~W} \cdot \mathrm{m}^{-2}, \mathrm{p}<0.001\right)$ when sweat rates increasing to $175 \mathrm{~g} / \mathrm{h}$ but with no significant difference between 175 and $250 \mathrm{~g} / \mathrm{h}(p>0.05)$. For other hydrophobic materials, i.e., pho-SI5, pho-MU9 and phoMU10, minimum $E_{\text {non-evap }}$ and $E_{\text {env }}$ statistically equaled to 0 at the three sweat rates $(p>0.05)$. The different increase trend of $E_{\text {env }}$ and $E_{\text {non-evap }}$ due to moisture increase could be due to different moisture wicking forms in materials, which will be further discussed in 3.2.

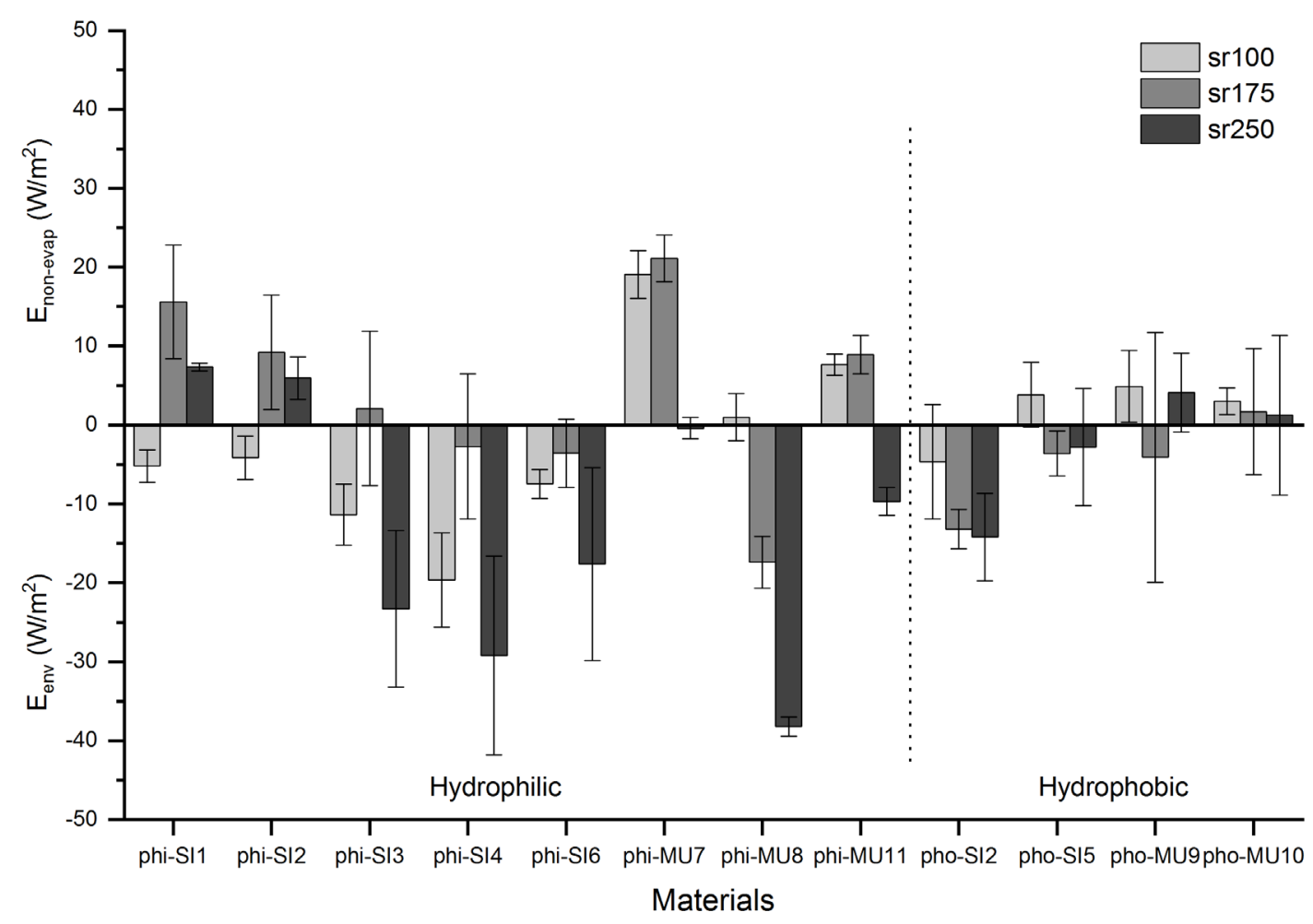

Figure 3. Minimum non-evaporative heat loss $\left(E_{\text {non-evap }}\right)$ and minimum environmental evaporative heat $\left(E_{\text {env }}\right)$ for SIs and MUs at three sweat rates (average values and standard deviations).

\subsection{Effect of sweat rate on apparent evaporative cooling efficiency and its interaction with mate- rial hydrophilicity and hydrophobicity}

Fig. $4 a$ and $4 b$ show the apparent evaporative cooling efficiency $(\eta)$ in relation to sweat rate. The graphs clearly demonstrated that the apparent evaporative cooling efficiency with continuous sweating is largely dependent on whether the material is hydrophilic or hydrophobic.

\subsubsection{Hydrophilic materials}

The sweat rate has significant effect on $\eta$ for all hydrophilic Sls $(p<0.05)$ and hydrophilic MUs $(p<$ 0.01 ), except phi-SI6 ( $p=0.170$ ). For hydrophilic SIs (Fig. 4a), $\eta$ was always higher at $175 \mathrm{~g} / \mathrm{h}$ than at $100 \mathrm{~g} / \mathrm{h}$ with an increase by $3-12 \%(p<0.05)$. However, the sweat rate of $250 \mathrm{~g} / \mathrm{h}$ did not show significant changes on $\eta(p>0.05)$ compared to that at $175 \mathrm{~g} / \mathrm{h}$, but overall $\eta$ showed a decrease trend by 2- 
$7 \%$. The efficiency variations with sweat rate may be explained by differences in the in-plane and transplanar wicking of liquid moisture. Higher sweat rates led to increasing clothing wetting area (in-plane wicking) (Fig. 4e) and clothing wetting depth (transplanar wicking). A larger clothing wetting area causes more evaporation and thus increases the evaporative cooling, may explaining the rise of the evaporative cooling efficiency. Fig. 4c presents the in-plane and transplanar wicking of hydrophilic single-layer material (phi-SI4) between different sweat rates from tomography tests. When sweat rate increased from 100 to $175 \mathrm{~g} / \mathrm{h}$, a larger amount of in-plane wicking occurred, as can be seen with a large amount of liquid near the skin (Fig. 4c). However, from sweat rate 175 to $250 \mathrm{~g} / \mathrm{h}$, moisture tended to be increasingly transported in transplanar direction, which may explain the decrease of evaporative cooling efficiency. This clearly shows that both evaporative area and evaporative locus determine the evaporative cooling efficiency and quantitatively demonstrates the opposite roles played by the two forms of wicking of liquid sweat.

For hydrophilic MUs (Fig. 4b), the evaporative cooling efficiency decreased by 2-9\% with increasing sweat rates $(p<0.05)$. A previous study [11] calculated the cooling efficiency for a sweating person with permeable clothing wetted with different amounts of water. For suits wetted to 0,400 , and 1,000 g, they observed the cooling efficiency decreasing from $77 \%$ to $35 \%$, which showed the same trend with our study. However, the values in their study are lower than that in our study (86 \%-113\%), which could be due to the higher air temperature in their study, which benefited the environment evaporative heat and did not allow the wet conduction and heat pipe effect. Further, the tomographic measurements (Fig. 4d) and infrared images (Fig. 4f) showed an increase in both in-plane and transplanar wicking for higher sweat rate. It can however be inferred that the disadvantage of transplanar wicking on evaporative cooling efficiency was greater than benefit brought by in-plane wicking.
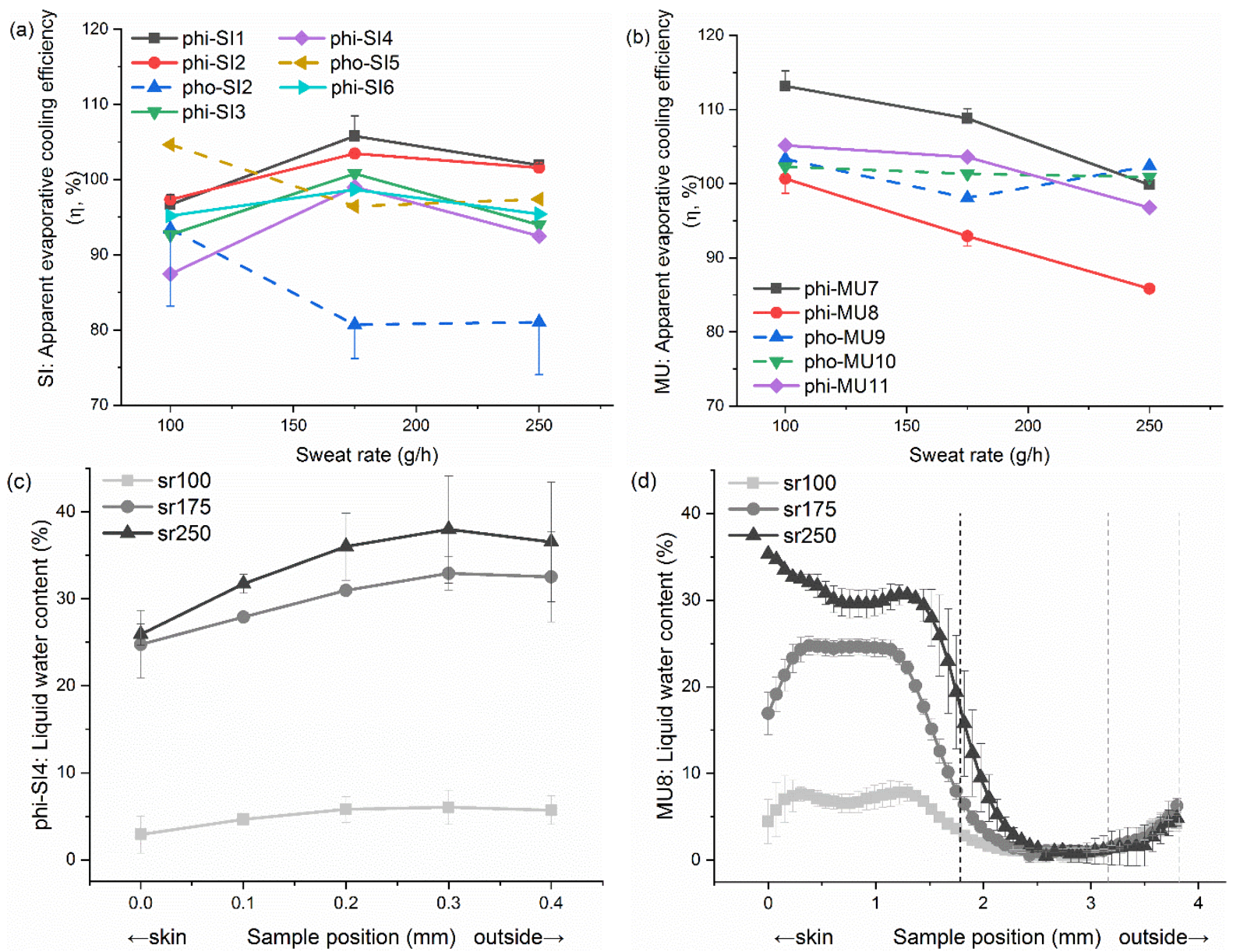
(e)
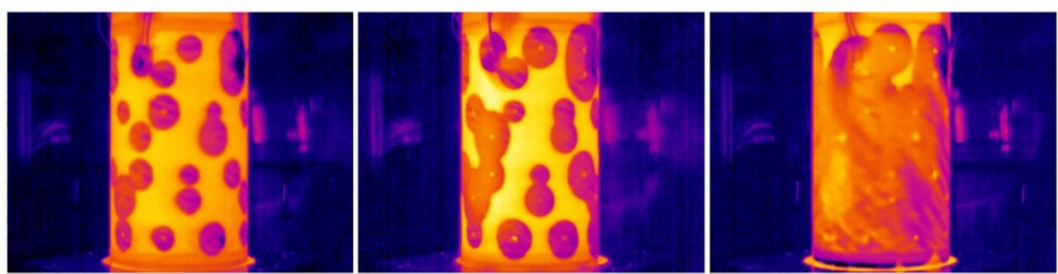

(f)
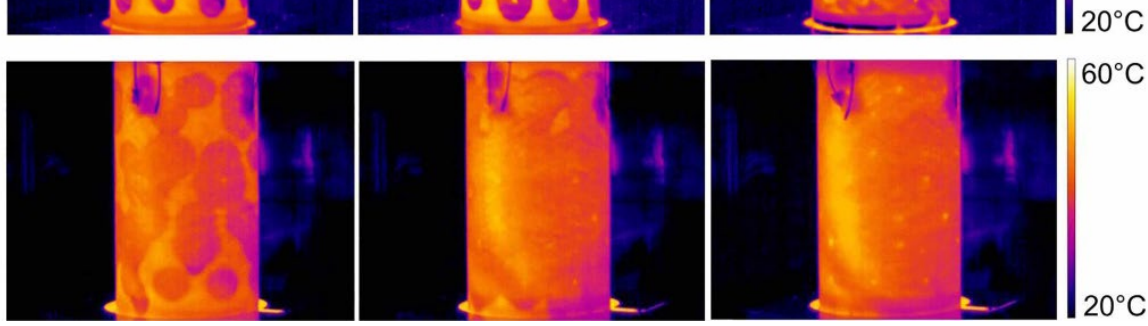

Figure 4. Relationship between apparent evaporative cooling efficiency and sweat rate. (a) SI, (b) MU (dashed lines: hydrophobic materials). X-ray tomography results: Liquid moisture distribution in phi-SI4 (c) and phi-MU8 (d) at three sweat rates in steady state. Infrared images of SI examples (phi-SI4, e) and MU examples (phi-MU8, f) at three sweat rates (Left to right: 100, 175, $250 \mathrm{~g} / \mathrm{h}$ ).

Fig. 5 presents the relationship between relative evaporation (R.E.) and apparent evaporative cooling efficiency $(\eta)$. Due to the sweat transfer within the material, the evaporation of sweat may come from both the torso surface (skin surface) and the clothing layers. This caused the actual evaporation rate $\left(\dot{m}_{\text {evap }}\right)$ higher than the traditionally calculated maximum evaporative capacity $\left(\dot{m}_{\text {evap, max }}\right)$, which only considers the evaporation from the skin surface, leading to the R.E. higher than 1.

For each set of symbol, $\eta$ showed a decrease trend with the increase of $R$.E.. That is, for each category of material (material category: single-layer material and multilayer material system) at a single sweat rate, $\eta$ decreases as $R$. E. increases. The decrease we see here should be due to the influence of material properties (e.g., material structure) in the same category of materials. The decrease trend is consistent with the study of Givoni et al. [10], which demonstrates that a relatively dry skin (low R.E.) leads to more evaporation on the skin, resulting in higher cooling efficiency, while with high R.E., part of the sweat is wicked to the clothes and evaporates there and the efficiency for skin cooling will be reduced.

However, if combing three groups of sweat rates and combining single-layer material and multilayer material system, within a certain R.E. range (less than 1.50 in our study), $\eta$ increases with the increase of R.E.. The rising trend we see here is due to the influence of sweat rate and the composition of the material system (i.e., single-layer or multilayer material).

Therefore, we can see that within a certain range, although R.E. is always on the rise, if the rise of R.E. is caused by the influence of material properties, $\eta$ decreases; if the rise of $R . E$. is due to increased sweat rate or material composition, $\eta$ increases. Thus, we infer that it may be limited to just use $R . E$ to measure the change in $\eta$. R.E. can be used to evaluate the skin wettedness, but cannot provide the distribution of wettedness. We consider that it is the moisture distribution in the material that determines the cooling efficiency. The increase trend at lower R.E. again demonstrates that the local liquid sweat in our cases may strengthen the positive effect of in-plane wicking on cooling efficiency. 


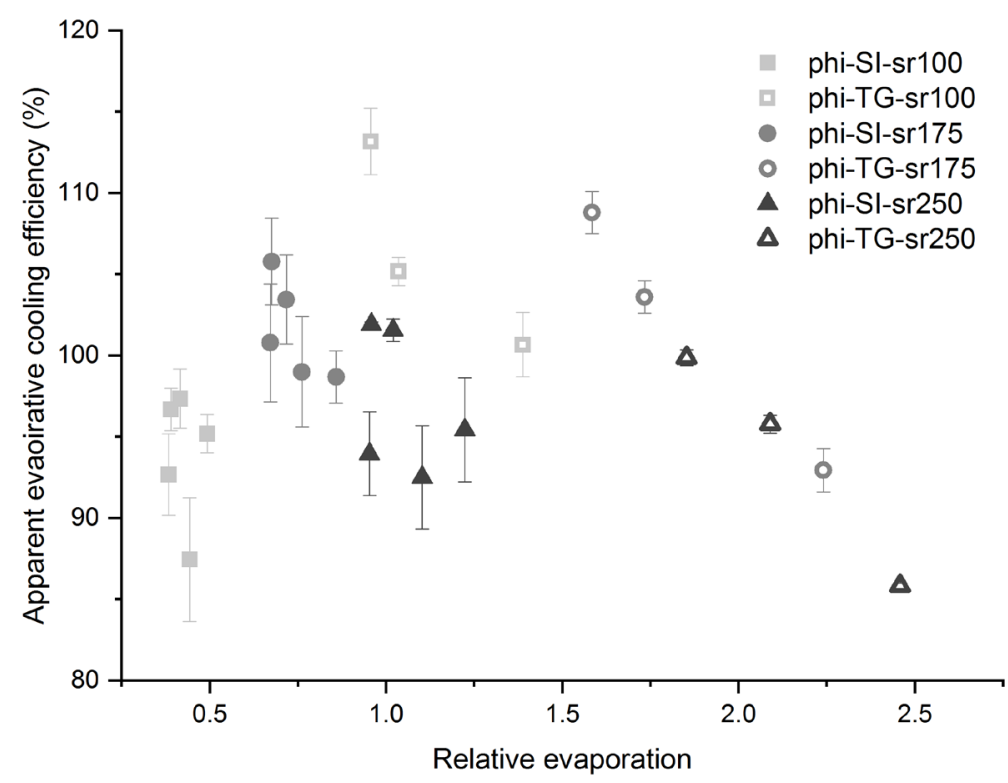

Figure 5. Relationship between relative evaporation (R.E.) and apparent evaporative cooling efficiency.

\subsubsection{Hydrophobic materials}

$\eta$ of pho-SI5, pho-MU9 and pho-MU10 at three sweat rates showed no significant difference from $100 \%$ $(p>0.05)$ (Fig.4a, 4b, dashed lines). This result indicates that for these hydrophobic materials, the amount of liquid sweat had no effect on the cooling efficiency due to negligible wicking effects. Therefore, all the evaporative heat may come from the human body. However, for pho-SI2, while $\eta$ at $100 \mathrm{~g} / \mathrm{h}$ sweat rate also showed no significant difference from $100 \%$, the values at 175 and $250 \mathrm{~g} / \mathrm{h}$ sweat rates were significantly lower than $100 \%(p<0.05)$, i.e. at least $19 \%$ evaporative heat came from the environment. This phenomenon may be explained by an increasing thickness of the sweat layer [10]: the formation of sweat drops on the skin induces a greater thermal resistance to the heat flow from the body to the evaporating surface, and thus, a larger fraction of the evaporative heat must be taken from the ambient, with a corresponding reduction in body cooling efficiency. This phenomenon was not observed in the other materials as these materials contained hygroscopic fibers (cotton for pho-SI5 and viscose for phoMU9 and pho-MU10) which absorbed the moisture and thus hindered the water drop formation at the interface between torso surface and fabric. These results indicate that both material hydrophobicity and hygroscopicity have an effect on evaporative cooling efficiency.

\subsection{Influence of other material properties on apparent evaporative cooling efficiency}

Fig. $4 a$ and $4 \mathrm{~b}$ shows that $\eta$ behaved differently for different hydrophilic materials, indicating that other material properties influenced the apparent evaporative cooling efficiency. We therefore performed multiple linear regression between the apparent evaporative cooling efficiency and the material properties (i.e., weight, thickness, $R_{c t}$ and $R_{e t}$ ) presented in Table 1 to determine the possible critical properties.

\subsubsection{Material evaporative resistance $R_{e t}$}

For hydrophilic Sls, the multiple linear regression did not show any significant effect of the measured material properties on $\eta(p>0.05)$. For hydrophilic MUs, $\eta$ showed a significant negative correlation with material $R_{e t}$ with $\mathrm{R}^{2}=0.73,0.96$ and $0.99(\mathrm{p}<0.001)$ at sweat rates 100,175 and $250 \mathrm{~g} / \mathrm{h}$, respectively (Fig. 6a), with a higher correlation coefficient for the higher sweat rates. The negative correlation may be explained by comparing the apparent evaporative heat loss $\left(E_{\text {app }}\right)$ and the total evaporative heat $\left(E_{\text {mass }}\right)$. As shown in Fig. $6 \mathrm{~b}$, when $R_{\text {et }}$ increased from 15.6 to $16.8 \mathrm{~m}^{2} \cdot \mathrm{Pa} / \mathrm{W}, E_{\text {app }}$ decreased and $E_{\text {mass }}$ increased at sweat rates 100 and $175 \mathrm{~g} / \mathrm{h}$; the increase of $E_{a p p}$ was lower than the increase of $E_{\text {mass }}$ at 
sweat rate $250 \mathrm{~g} / \mathrm{h}$. When $R_{e t}$ increased from 16.8 to $23.9 \mathrm{~m}^{2} \cdot \mathrm{Pa} / \mathrm{W}$, the decrease of $E_{a p p}$ was higher than the decrease of $E_{\text {mass }}$ at the three sweat rates. For further reasoning, we have two assumptions here. Assumption I: Higher $R_{e t}$ tended to decrease the evaporative heat loss from torso $\left(E_{\text {real }}\right)$. Assumption II: we assume that higher $R_{e t}$ tended to increase both $E_{\text {non-evap }}$ and $E_{\text {env }}$. The reason is as below: it is straightforward that a greater $R_{e t}$ may cause more vapor condensation (and thus a higher heat pipe effect, which contributes to $E_{\text {non-evap }}$ ); the greater amount of accumulated water increased wet conduction (the other contributor to $E_{\text {non-evap }}$ ) and possibly also environmental evaporative heat $\left(E_{\text {env }}\right)$. Therefore, the variations of $E_{\text {app }}$ and $E_{\text {mass }}$ with $R_{e t}$ (Fig. 6b) demonstrates that the increase of $E_{\text {env }}$ due to greater $R_{e t}$ was higher than the increase of $E_{\text {non-evap }}$. Fig. $6 \mathrm{c}$ presents the infrared images (surface temperatures) of the clothed torso for the three hydrophilic MUs. The wet surface temperature of phiMU8 $\left(24.07 \pm 0.06{ }^{\circ} \mathrm{C}\right.$ ) was the lowest among all MUs (phi-MU7: $25.75 \pm 0.07{ }^{\circ} \mathrm{C}$; phi-MU11: $25.33 \pm 0.15^{\circ} \mathrm{C}$ ), which may also be an evidence for the higher $E_{\text {env }}$ in phi-MU8, which has the greatest $R_{e t}$.
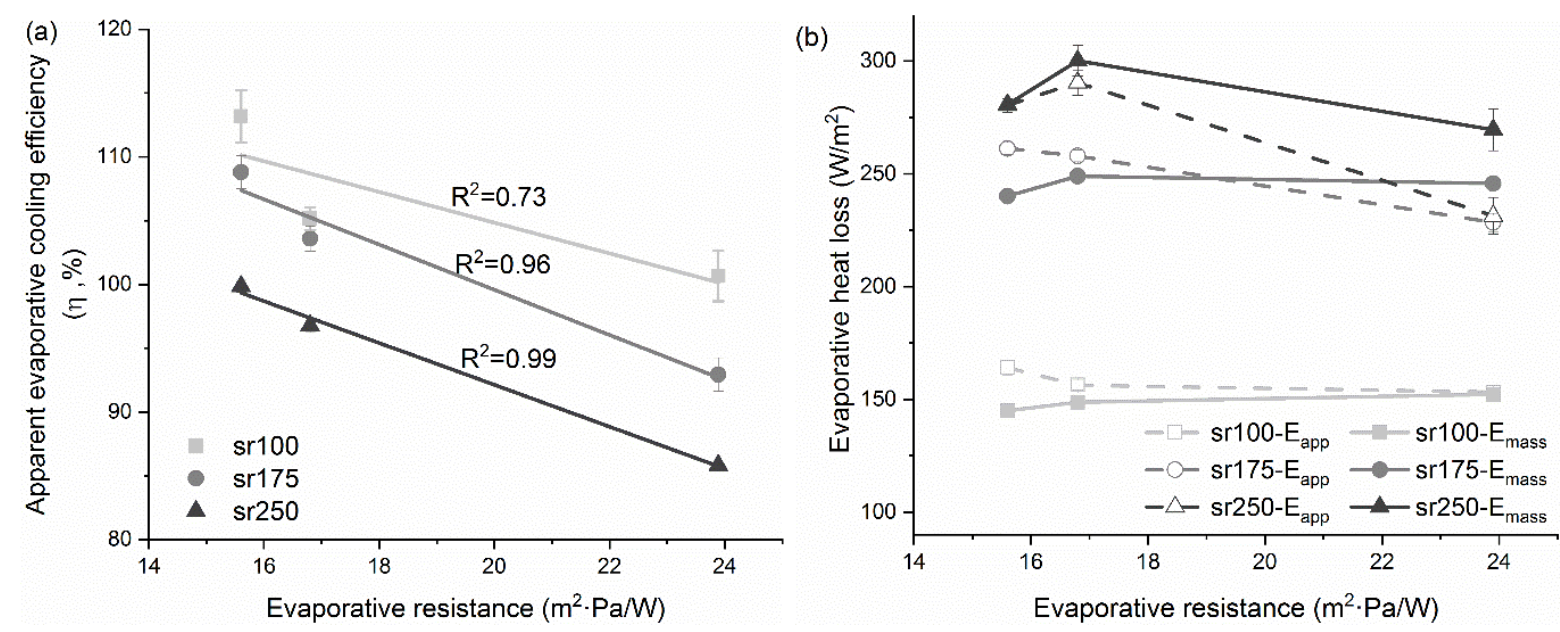

(c)
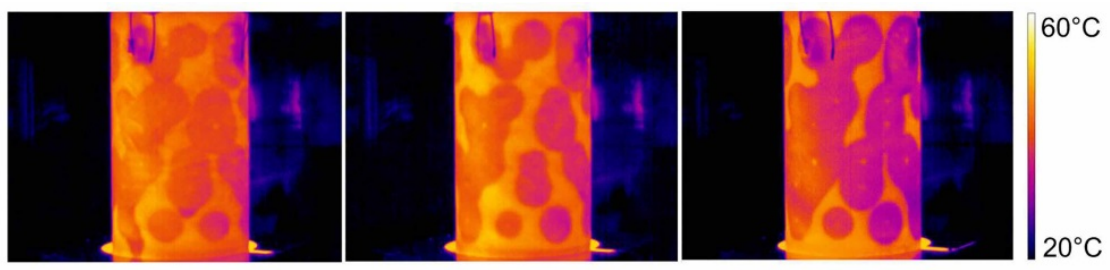

Figure 6. (a) Relationship between apparent evaporative cooling efficiency and evaporative resistance for hydrophilic MUs. sr100, sr175 and sr250: sweat rate 100, 175 and $250 \mathrm{~g} / \mathrm{h}$. (b) Relationship between apparent evaporative heat loss

$\left(E_{a p p}\right)$ /evaporative cooling potential $\left(E_{\text {mass }}\right)$ and evaporative resistance for hydrophilic MUs. (c) Infrared images of clothed torso at sweat rate $100 \mathrm{~g} / \mathrm{h}$ in the steady state of phase 2 . Left to right: phi-MU7, phi-MU11 and phi-MU8 with $\boldsymbol{R}_{e t}$ increasing from 15.6 to $23.9 \mathrm{~m}^{2} \cdot \mathrm{Pa} / \mathrm{W}$.

\subsubsection{Material thickness}

Fig. 7 shows that the variation of apparent evaporative cooling efficiency $(\Delta \eta)$ from sweat rate 100 to $175 \mathrm{~g} / \mathrm{h}$ linearly decreased with increasing material thickness (i.e., $5 \%$ decrease per $\mathrm{mm}$ for sweat rates from 100 to $175 \mathrm{~g} / \mathrm{h}, \mathrm{R}^{2}=0.93, \mathrm{p}<0.05$ ). This result indicates that when increasing sweat rate, the liquid moisture in thicker material tends to have a higher transplanar wicking than in-plane wicking and thus more latent heat will be obtained from the environment. This hypothesis can be confirmed by Fig. 4c and $4 \mathrm{~d}$, in which the transplanar wicking of the thicker phi-MU8 was higher than that of phi-SI4. But from sweat rate 175 to $250 \mathrm{~g} / \mathrm{h}$, material thickness did not show a significant effect on $\Delta \eta\left(R^{2}=0.25, p>0.05\right)$, which may be due to the liquid saturation $\mathrm{s}$ on the whole thickness of the material. 


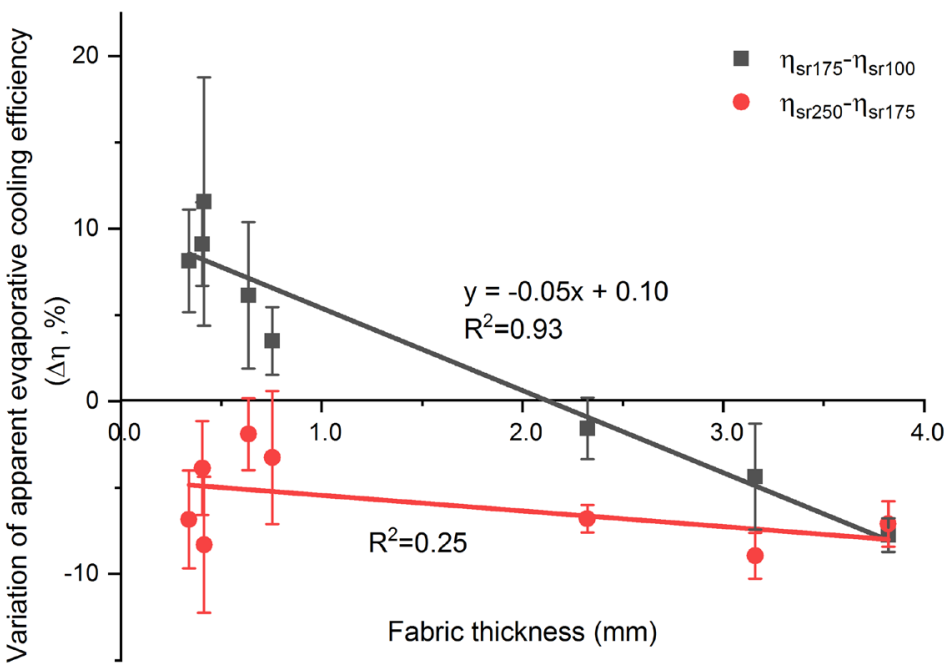

Figure 7. Hydrophilic materials: relationship between the variation of apparent evaporative cooling efficiency and fabric thickness. $\eta_{s r 175}-\eta_{s r 100}$ : variation of apparent evaporative cooling efficiency from sweat rate 100 to $175 \mathrm{~g} / \mathrm{h}$; $\eta_{s r 175}-\eta_{s r 100}$ : variation of apparent evaporative cooling efficiency from sweat rate 175 to $250 \mathrm{~g} / \mathrm{h}$.

\section{Conclusion}

Our study investigated the complex mechanisms of evaporative cooling efficiency of clothed human body with continuous sweating. It presented that evaporative cooling efficiency under continuous sweating behaves differently from that with pre-wetted fabric "skin". Under continuous sweating, the error ratios of traditional evaporative heat loss determination based on mass loss is $-24.2-15.3 \%$. We further demonstrated the effect of different continuous sweat rates on evaporative cooling efficiency and the influence of material hydrophilicity/hydrophobicity. For hydrophilic materials, the dual role (in-plane and transplanar) played by wicking of perspired moisture on the evaporative cooling efficiency was quantified. We showed that for a sweat rate increase, the in-plane transfer of moisture increased the evaporative cooling efficiency by up to $12 \%$ while the transplanar transfer of moisture may reduce the evaporative cooling efficiency by up to $9 \%$. This showed that both evaporative area and evaporative locus were determinants for the evaporative cooling efficiency. The evaporative cooling efficiency was less affected by different levels of perspiration for hydrophobic materials due to low wicking. Furthermore, it was shown that the evaporative cooling efficiency of hydrophilic material systems was negatively correlated with the fabric evaporative resistance and fabric thickness. The study reveals the necessity of combined analyses of both moisture wicking and evaporation and contributes to the understanding of effective sweat cooling of clothed human body during high-intensity activities.

\section{Reference}

1. Nagata, H., Evaporation of sweat on clothed subject. Nippon Eiseigaku Zasshi (Japanese Journal of Hygiene), 1962. 17(3): p. 155-163.

2. Hall, J.F., Effect of vapor pressure on physiologic strain and body heat storage. J Appl Physiol, 1963. 18: p. 808-11.

3. Candas, V., J.P. Libert, and J.J. Vogt, Human skin wettedness and evaporative efficiency of sweating. J Appl Physiol Respir Environ Exerc Physiol, 1979. 46(3): p. 522-8.

4. Candas, V., J.P. Libert, and J.J. Vogt, Influence of air velocity and heat acclimation on human skin wettedness and sweating efficiency. J Appl Physiol Respir Environ Exerc Physiol, 1979. 47(6): p. 1194-200.

5. Alber-Wallerstrom, B. and I. Holmer, Efficiency of sweat evaporation in unacclimatized man working in a hot humid environment. Eur J Appl Physiol Occup Physiol, 1985. 54(5): p. 480-7. 
6. Havenith, G., et al., Apparent latent heat of evaporation from clothing: attenuation and "heat pipe" effects. J Appl Physiol (1985), 2008. 104(1): p. 142-9.

7. Havenith, G., et al., Evaporative cooling: effective latent heat of evaporation in relation to evaporation distance from the skin. J Appl Physiol (1985), 2013. 114(6): p. 778-85.

8. Gagge, A.P. and Y. Nishi, Heat exchange between human skin surface and thermal environment. Comprehensive Physiology, 2011.

9. Kondo, N., T. Nishiyasu, and H. Ikegami, The influence of exercise intensity on sweating efficiency of the whole body in a mild thermal condition. Ergonomics, 1996. 39(2): p. 225-231.

10. Givoni, B. and H.S. Belding, The cooling efficiency of sweat evaporation. 1962.

11. Craig, F.N. and J.T. Moffitt, Efficiency of evaporative cooling from wet clothing. J Appl Physiol, 1974. 36(3): p. 313-6.

12. Rossi, R.M., et al., Transplanar and in-plane wicking effects in sock materials under pressure. Textile Research Journal, 2011. 81(15): p. 1549-1558.

13. Tang, K.P., et al., Characterizing the transplanar and in-plane water transport properties of fabrics under different sweat rate: Forced Flow Water Transport Tester. Sci Rep, 2015. 5: p. 17012.

14. Tang, K.P., et al., Characterizing the transplanar and in-plane water transport of textiles with gravimetric and image analysis technique: Spontaneous Uptake Water Transport Tester. Sci Rep, 2015. 5: p. 9689.

15. Wang, F., et al., Real evaporative cooling efficiency of one-layer tight-fitting sportswear in a hot environment. Scand J Med Sci Sports, 2014. 24(3): p. e129-39.

16. Nagata, H., Evaporative heat loss and clothing. J Hum Ergol (Tokyo), 1978. 7(2): p. 169-75.

17. Givoni, B., Elements of heat exchanges between man and his thermal environment, in Man, climate and architecture. 1981, Applied Science Publishers.

18. ISO18640-1:2018, Protective clothing for firefighters -- Physiological impact -- Part 1: Measurement of coupled heat and moisture transfer with the sweating torso. 2018, International Organization for Standardization: Geneva, Switzerland. p. 38.

19. ISO18640-2:2018, Protective clothing for firefighters -- Physiological impact -- Part 2: Determination of physiological heat load caused by protective clothing worn by firefighters. 2018, International Organization for Standardization: Geneva, Switzerland. p. 17

20. Zimmerli, T. and M.S. Weder, Protection and comfort-a sweating torso for the simultaneous measurement of protective and comfort properties of PPE, in Performance of protective clothing: Sixth Volume. 1997, ASTM International. p. 271-280.

21. Annaheim, S., et al., A new method to assess the influence of textiles properties on human thermophysiology. Part I. International Journal of Clothing Science and Technology, 2015. 27(2): p. 272-282.

22. ISO 3801:1977, Textiles -- Woven fabrics -- Determination of mass per unit length and mass per unit area. 1977, International Organization for Standardization: Geneva, Switzerland.

23. ISO 5084:1966, Textiles -- Determination of thickness of textiles and textile products. 1996, International Organization for Standardization: Geneva, Switzerland.

24. ISO 11092:2014, Textiles -- Physiological effects -- Measurement of thermal and water- vapour resistance under steady-state conditions (sweating guarded-hotplate test). 2014, International Organization for Standardization: Geneva, Switzerland.

25. Wang, F., et al. Clothing real evaporative resistance determined by means of a sweating thermal manikin: a new round-robin study. in 10th Manikin and Modelling Meeting (10i3m), Tampere, Finland. 2014.

26. Stämpfli, R., et al., X-ray tomographic investigation of water distribution in textiles under compression - Possibilities for data presentation. Measurement, 2013. 46(3): p. 1212-1219.

27. Field, A., Discovering statistics using IBM SPSS statistics. 2013: Sage.

28. Chen, Y., J. Fan, and W. Zhang, Clothing thermal insulation during sweating. Textile Research Journal, 2003. 73(2): p. 152-157.

29. Bröde, P., et al., Non-evaporative effects of a wet mid layer on heat transfer through protective clothing. European journal of applied physiology, 2008. 104(2): p. 341-349.

30. Richards, M.G., et al., Dry and wet heat transfer through clothing dependent on the clothing properties under cold conditions. Int J Occup Saf Ergon, 2008. 14(1): p. 69-76. 
31. Wissler, E.H. and G. Havenith, A simple theoretical model of heat and moisture transport in multi-layer garments in cool ambient air. Eur J Appl Physiol, 2009. 105(5): p. 797-808.

\section{Acknowledgements}

The authors would like to thank DuPont, Switzerland and Trans-Textil, Germany for supplying the fabrics for this study and appreciate the technical support from Max Aeberhard, Ivo Rechsteiner and Rolf Stämpfli during the laboratory tests. The authors would like to acknowledge the Fundamental Research Funds for the Central Universities (Grant NO. 2232018G-08), the financial support from the National Nature Science Foundation (Grant NO. 51576038), and Shanghai Municipal Natural Science Foundation (Grant NO. 17ZR1400500). The authors also gratefully acknowledge financial support from the China Scholarship Council.

\section{Author Contributions}

L.J., A.S and R.R supervised the research process. G.M. conceptualized the manuscript and conducted the torso experiments. C. A. provided technical support. G.M. analyzed the data and wrote the manuscript. A.S, P.A., C.A., L.J and R.R. gave scientific advice. R.R. gave substantial suggestions on manuscript writing. All authors contributed to discussion and reviewed the manuscript.

\section{Additional Information}

Competing Interests: The authors declare that they have no competing interests. 